\title{
Change in ozone depletion rates beginning in the mid 1990s: trend analyses of the TOMS/ SBUV merged total ozone data, 1978-2003
}

\author{
J. W. Krzyścin \\ Institute of Geophysics, Polish Academy of Sciences, Warsaw, Poland \\ Received: 18 October 2005 - Revised: 16 January 2006 - Accepted: 23 January 2006 - Published: 23 March 2006
}

\begin{abstract}
Statistical analyses have been applied to the gridded monthly means of total ozone from combined TOMS and SBUV measurements (version 8 of the data) for the period 1978-2003. We focus on the detection of a change in the trend pattern by searching for a turnaround in the previous downward trend. The ozone time series have been examined separately for each grid point and season, taking into account the various descriptions of the trend term: double-linear, proportional to the index of the overall chlorine content in the stratosphere, and a smooth curve without an a priori defined shape (the output of the regression model). Standard explanatory variables representing physical and chemical processes known to influence the ozone distribution have been considered: $\mathrm{Mg}$ II index, QBO wind at 10 and $30 \mathrm{hPa}$, zonal wind anomalies at $50 \mathrm{hPa}$ along the $60^{\circ}$ north or $60^{\circ}$ south circle, the index of the stratospheric aerosols loading in the $\mathrm{NH}$ or $\mathrm{SH}$, and the tropopause pressure. The multivariate adaptive regression splines methodology is used to find an optimal set of the explanatory variables and shape of the trend curve. The statistical errors of the models' estimates have been calculated using block bootstrapping of the models' residuals. The results appear to be consistent among models using different formulations of the trend pattern. The 2003 level of total ozone after the removal of the variations due to the parameterized dynamical/chemical forcing on the ozone is still below the long-term (1978-2003) mean level over the extratropical regions. The deficit is $\sim 2-5 \%$ in the $\mathrm{NH}$ and much larger in the $\mathrm{SH}$ and exhibits clear seasonal variability, $\sim 15 \%$ in autumn, $\sim 10 \%$ in winter, and $\sim-5 \%$ in spring and summer. The present total ozone level is higher beyond the tropics than that in the mid 1990s but it is too early to announce a beginning of the ozone recovery there because of the trend uncertainties, due to errors of the regression estimates for individual grid points and longitudinal
\end{abstract}

Correspondence to: J. W. Krzyścin

(jkrzys@igf.edu.pl) variability of the trend pattern. A rigorous statistical test has shown the statistically significant turnaround for some grid points over the extratropical region and a deepening of the ozone negative trend has not been found for any grid point.

Keywords. Atmospheric composition and structure (Middle atmosphere-composition and chemistry) - Meteorology and atmospheric dynamics (Climatology; Middle atmosphere dynamics)

\section{Introduction}

Implementation of international controls on ozone depleting substances (ODS) stimulated by the Montreal protocol (1987) and subsequent amendments resulted in a slower rate of increase in the stratosphere contamination by ODS observed in the beginning of the 1990s (WMO, World Meteorological Organization, 1999) and the appearance of a declining tendency in the total chlorine abundance at the end of the 1990s (WMO, 2003). The question arises - when are we able to disclose the first sign of the ozone layer returning back to its undisturbed (pre-1970) level?

Recent statistical analyses of the upper stratospheric (Newchurch, et al., 2003; Cunnold et al., 2004), and total column amount of ozone (Reinsel et al., 2005, Dhomse et al., 2005) showed that the strong declining trend observed in the 1980s and the early 1990s has not continued and the very first beginning of a slow return back to the 1970 level has been started in the mid 1990s. In the upper stratosphere chemical reactions between chlorine and ozone mostly determine the ozone content there. However, in the lower stratosphere, where $80-90 \%$ of the stratospheric ozone resides, both chemical and dynamical factors can affect the ozone level. Although chemical causes of the ozone depletion are relatively well known, the dynamical factors controlling the long-term behaviour of the stratospheric ozone are not fully understood;

Published by Copernicus GmbH on behalf of the European Geosciences Union. 
this is manifested by the difference found between the observed and modeled trends (Chipperfield, 2003; Rosenfield et al., 2005). It is difficult to separate the chemical and dynamical processes responsible for the ozone variations in the lower stratosphere. For example, changes in the thermal structure of the stratosphere induced by greenhouse gases affect the wind field, which controls the ozone transport and other long-lived chemicals important for the ozone chemistry. The atmospheric chemistry and transport are strongly coupled and the level of coupling is not well understood precluding a precise estimation of the anthropogenic component of the total ozone long-term changes. Moreover, uncertainties in predicting and determining the peak abundances of ODS complicate the timing of ozone recovery. Thus, many factors interfere by adding a considerable uncertainty to determining a possible turnaround in the ozone trends.

Almost all previous estimates of the long-term ozone changes employed a multiple regression technique, thereby extracting a trend from the analyzed time series. Some past trend studies estimated the rate of ozone decline as a slope of a straight line calculated in a regression model which also accounts for the ozone variations related (linearly) to the changes in the atmospheric circulation and external solar forcing (e.g. Bojkov et al., 1996). Past trend studies revealed a trend dependence on the time interval over which it was calculated, supporting a suggestion of a nonlinear shape of the trend (Fioletov et al., 2002). Classical multiple regression models with an a priori selected functional form of ozone long-term pattern (e.g. "hockey stick" pattern), as well as a linear response of the ozone to the forcing factors, appear not be to well suited when searching for the first steps of the ozone restoration.

In this study, we first review statistical models which incorporate a possible change in the trend, and apply them to the analysis of the gridded satellite total ozone data (TOMS/SBUV merged data), to reveal zonal changes in the declining rate of total ozone. A comparison of the models' results allows specific insight into the recovery processes of the atmospheric ozone.

\section{Satellite ozone data}

The satellite data set, Version 8 TOMS/SBUV, was prepared at NASA/Goddard Space Flight Center by merging data from the total ozone mapping spectrometer (TOMS) and solar backscatter ultraviolet (SBUV) instruments. Measurements from different instruments were calibrated to the 1996-1999 level of the TOMS instrument on board of the Earth Probe (EP) satellite to make the time series internally homogeneous. In constructing the merged data, Frith et al. (2004) used inter-instrument differences for the overlapped periods to determine offsets used further for other instruments' adjustments to the EP ozone. The time series and additional documentation are available at http://code916.gsfc.nasa.gov/Data_services/merged. The gridded data $\left(10^{\circ} \times 30^{\circ}\right.$ latitude $\times$ longitude $)$ will constitute an input to various trend models, as described in Sect. 3. The TOMS/SBUV V8 data corresponds to other global total ozone data from satellite observations (GOME, SBUV V8, Dhomse et al., 2005) and ground-based Dobson network (Harris et al., 2003).

The monthly mean of total ozone in running month $t$, $\mathrm{O}_{3}(t)$, has been converted to the fractional deviation, i.e. deviation relative to the long-term (1978-2003) monthly mean expressed in $\%$ of the long-term mean, $\Delta \mathrm{O}_{3}(t)=\left(\mathrm{O}_{3}(\mathrm{t})-\mathrm{O}_{3}^{*}\right.$ (month, $t)) / \mathrm{O}_{3}^{*}(\text { month, } t)^{*} 100 \%$, where $\mathrm{O}_{3}(\mathrm{t})$ denotes the monthly mean of total ozone for a selected grid point in running month $t, t=1$ at the beginning, $t=T$ at the end of the time series, and $\mathrm{O}_{3}^{*}$ (month, $t$ ) represents the long-term monthly mean for calendar month, regarding the running month $t$.

\section{Trend models}

The interannual fluctuations in the atmospheric ozone are a superposition of the effects due to changes in the anthropogenic ozone depleting substances, solar flux, and changes in the stratospheric circulation patterns (yielding a redistribution of ozone rather than steady changes in the global ozone pattern). To determine long-term changes in ozone it is desirable to separate influences of various dynamical and chemical processes. A multiple regression technique has been frequently used to extract a trend pattern from the analyzed time series. The trend means a continuing and smooth change over a given period with also a stable and persistent cause (sometimes difficult to identify). The rate of ozone decline has been taken as a slope of the smooth curve fitted to the ozone time series after filtering out variations induced by fluctuations in the atmospheric circulation and external solar forcing. The regression models used have the general form:

$$
\begin{aligned}
& \Delta \mathrm{O}_{3}(t)=\text { const }+\operatorname{Trend}(t)+\text { Oscillations }\left(X_{1}(t), \ldots, X_{n}(t)\right) \\
& \quad+\operatorname{Noise}(t), \quad t=1, \ldots, T,
\end{aligned}
$$

where Trend $(t)$ represents a trend term, i.e. a slowly varying component of the ozone time series that is thought to be driven by anthropogenic long-term changes in the atmospheric chemistry and as yet unexplained long-term dynamical processes in the atmospheric dynamics. Oscillation $\left(X_{1}(t), \ldots, X_{n}(t)\right)$ represents the part of the ozone variations linked to specific variations in the atmospheric dynamics (e.g. the Brewer-Dobson circulation pattern) and also is related to intermittent chemical processes affecting the ozone layer usually after large volcanic eruptions; $X_{(\ldots)}(t)$ denotes a proxy (model's regressor) for the ozone changes driven by a specific process in the atmospheric dynamics and/or shortterm chemistry; $n$ gives the total number of such proxies; Noise $(t)$ represents the noise term that can be partially linked to the presently unknown short-term forcing yielding some 
autocorrelations in the noise term (usually with 1-month lag); const is a normalization constant providing a zero value for the overall mean of the fractional deviations.

Knowledge of different sources for total ozone variations, especially a reduction in halogen emissions in the late 1990s (WMO, 2003), suggests that the trend term can no longer be modeled in a linear fashion. Recently, various nonlinear forms for the trend term have been examined to describe the expected lessening of the ozone decline since the mid 1990s. Focusing on the detection of a turning point in the linear trend behaviour Reinsel et al. (2002) proposed the piecewise linear trend term,

$\operatorname{Trend}_{\text {double-linear }}(t)=\alpha_{1} \times t+\alpha_{2} \times\left(t-t_{0}\right)_{+}$,

where $\left(t-t_{0}\right)_{+}=t-t_{0}$ when $\mathrm{t}>\mathrm{t}_{0}$ and 0 otherwise, $\alpha_{1}$ gives the rate of ozone change since the beginning of the time series up to turning point $t_{0}$, and $\alpha_{2}$ represents a change in the rate of ozone change since the turning point, providing an overall rate of change $\alpha_{1}+\alpha_{2}$ after $t_{0}$. The piecewise linear trend concept has been incorporated in recent trend analyses (e.g. Reinsel et al., 2005). In the text below this model is called the double-linear trend model.

The linear trend term was traditionally linked with the gas phase chemical ozone destruction, as expected, from a steady increase in the stratospheric chlorine loading lasting up to the early 1990s. In recent years, when the atmosphere contamination by ODS tends to be lower it seems to be still meaningful to describe an anthropogenic ozone trend as being proportional to the overall content of these substances in the stratosphere. Thus, in this way the variability of the rate in ozone decline can be parameterized and the turnaround time is defined as the moment of the peak of EESC (Equivalent Effective Stratospheric Chlorine). This quantity combines the destructive power of all the chlorine and bromine containing species that are weighted with their individual ozone depleting potentials. EESC has peaked in 1997 and started a slow decline afterwards, as displayed in Fig. 1. The EESC time series looks to be a very promising proxy for the description of changes in the ozone trend pattern,

Trend $_{\text {chlorine }}=\beta \times E E S C(t)$,

where the $\operatorname{EESC}(t)$ pattern is derived from chemical-physical model simulations. Data used in the paper were obtained from the European Environment Agency web site www.eea.eu.int. The EESC trend model has been widely used in recent statistical analyses of the atmospheric ozone, (e.g. Newman et al., 2004; Yang et al., 2005; and Dhomse et al., 2005). Below this model is called the chlorine trend model.

The assumption that the long-term total ozone changes follow the EESC pattern or have the piecewise linear form is not necessarily valid. Moreover, the double-linear trend model needs a priori defined timing of the turnaround in the trend pattern and the EECS trend model sets exactly the ratio between the declining and increasing tendency after the

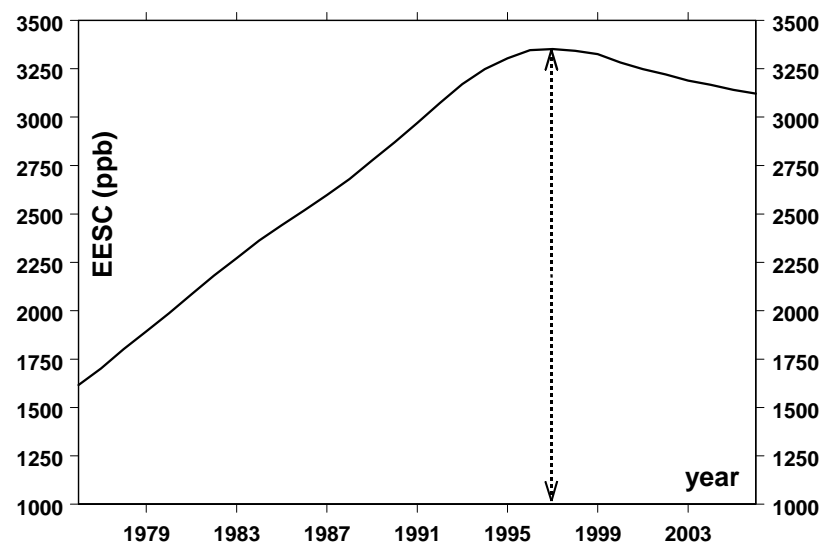

Fig. 1. The EESC time series as proposed by the European Environment Agency.

turnaround. To provide more freedom in the description of the trend variability Harris et al. (2001) proposed a flexible trend model,

Trend $_{\text {flexible }}(t)=$ Smooth Curve $(t)$,

where Smooth Curve(t) is not an a priori defined function but is extracted from the ozone time series by a two-step regression procedure, also taking into account regression terms responsible for the ozone variations driven by changes in the atmospheric dynamics. Harris et al. (2003) used the flexible trend model in the determination of the long-term variations in total ozone from global ground-based and satellite observations. Krzyścin (2004) and Krzyścin et al. (2005) proposed models which allow for even more freedom when searching for the trend component in the ozone time series. Białek (2006) used the flexible trend model for searching for changes in the ozone distribution shape by examination the time series of various statistical characteristics of groundbased ozone data (median, standard deviation, the maximum, and the minimum).

\section{The ozone explanatory variables}

In statistical models the ozone responses to known processes, acting on short- and long-term time scales, have been usually parameterized as a linear function of the ozone proxies (explanatory variables),

Oscillation $\left(X_{1}(t), \ldots, X_{n}(t)\right)=\gamma_{1} X_{1}(t)+\ldots+\gamma_{n} X_{n}(t) .(5)$

The proxies $X_{k}$ most commonly used in recent trend modeling (Steinbrecht et al., 2003; Dhomse et al., 2005) and also in this paper are: solar activity index $(10.7 \mathrm{~cm}$ solar radio flux or $\mathrm{Mg}$ II index, giving a solar irradiance variability in the UV range), QBO index (zonal component of the wind 


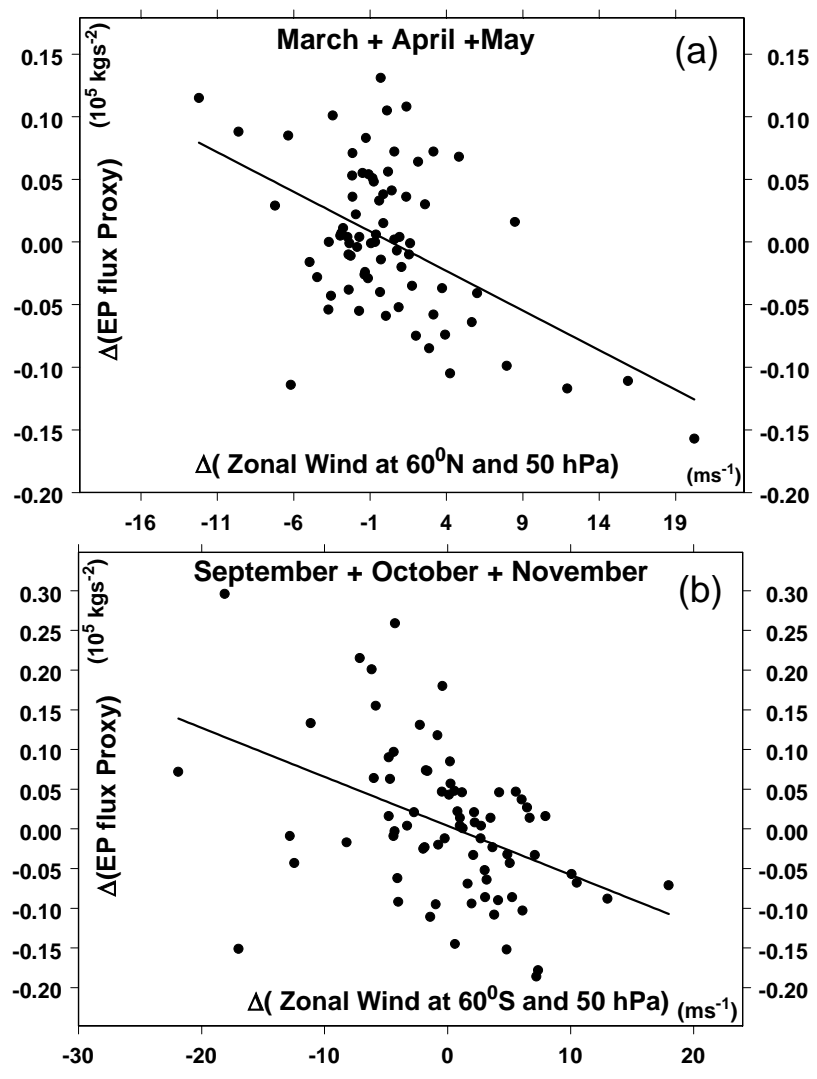

Fig. 2. Comparison of the proxies for the Brewer-Dobson circulation effects on total ozone. EP flux proxy versus zonal wind along a $60^{\circ}$ circle at $50 \mathrm{hPa}$; (a) Northern Hemisphere in spring, (b) Southern Hemisphere in autumn.

over the tropics at $30 \mathrm{hPa}$ and $10 \mathrm{hPa}$ ), index of the aerosols loading in the stratosphere being a response to volcanic eruptions (aerosol optical thickness at $550 \mathrm{~nm}$ provided by NASA Goddard Institute of Space Studies).

Recently, it has been established that the strength of the Brewer-Dobson circulation, which controls the winter ozone buildup at high latitudes and subsequent ozone transport to the mid-latitudes during the migration of the polar vortex and its final breakup, is an essential ozone explanatory variable (Randel et al., 2002; Hood and Souharev, 2005). Cumulative eddy heat flux at $100 \mathrm{hPa}$, averaged over the extratropical region, is used as a proxy for describing the changes in the Brewer-Dobson circulation pattern and strength of the polar vortex (e.g. Reinsel et al., 2005; Dhomse et al., 2005). Steinbrecht et al. (2003) introduced the zonal wind anomalies at $50 \mathrm{hPa}$ along the $60^{\circ}$ north and $60^{\circ}$ south circle as the proxy for both the magnitude of the meridional transport in the Brewer-Dobson circulation and the polar vortex strength in the $\mathrm{NH}$ and $\mathrm{SH}$, respectively. We have found that the cumulative eddy heat flux, as defined by Dhomse et al. (2005), and the zonal wind proxy are correlated (see Fig. 2). Both proxies have been examined here and we decided to use the latter because of its higher percentage of the explained variance.

In recent trend models various proxies were proposed to describe the impact of short-term meteorological variability on total ozone: temperature at various levels in the troposphere and stratosphere (Harris et al., 2003; Steinbrecht et. al., 2003; Krzyścin et al., 2005), potential vorticity (PV) at 350-K level (Hood and Souharev, 2005), and the tropopause height (Krzyścin et al., 1998; Steinbrecht et al., 1998; Varotsos et al., 2005). These proxies resolve much of the variations of the ozone time series but the resulting trends should be treated with caution in the case of the application of nondetrended local meteorological proxies. Such proxies can generate spurious lessening (or amplification) of the ozone trend. Regression constants pertaining to local dynamics proxies are derived from the statistical relationship which is valid for shorter time scales, and using them in parameterization processes describing much longer time scales may lead to an erroneous description of the ozone trend. Here the detrended time series of PV at 350-K level and the tropopause pressure (both from the NCEP/NOAA reanalysis data base, Kistler et al., 2001) have been examined as possible shortterm dynamical proxies. Finally, we selected the tropopause pressure as the proxy which is better correlated with total ozone. It should be noted that the tropopause proxy is somewhat correlated with the index of the North Atlantic Oscillations (or Arctic Oscillations) which was frequently used in recent studies of the long-term ozone fluctuations (e.g. Appenzeller et al., 2000; Reinsel et al., 2005). The tropopause proxy is probably also correlated with zonal wind at $60^{\circ} \mathrm{N}$.

There were a limited number of models examining the possibility of the nonlinear dependence of the ozone response to the forcing factors. Krzyścin et al. (2005) showed that total ozone variations from the European ground-based network could be effectively resolved assuming a linear response to the examined proxies, and interactions between the proxies helped only a little to resolve variability of the ozone time series. However, the examination of the individual stations data (Krzyścin, 2004) showed that by taking into account the model's simplicity and effectiveness, it was better to use an additive formula in the parameterization of the regressors' effects on ozone,

$$
\begin{aligned}
& \text { Oscillation }\left(X_{1}, \ldots, X_{n}\right)= \\
& \sum_{p 1}\left(\gamma_{p 1,+} *\left(X_{1}(t)-X_{0, p 1}\right)_{+}+\gamma_{p 1,-} *\left(X_{1}(t)-X_{0, p 1}\right)_{-}\right) \ldots+\ldots \\
& \sum_{p n}\left(\gamma_{p n,+} *\left(X_{n}(t)-X_{0, p n}\right)_{+}+\gamma_{p n,-} *\left(X_{n}(t)-X_{0, p n}\right)_{-}\right)(6)
\end{aligned}
$$

where " $(\ldots)_{+}$" denotes the positive part (i.e. $\left(y-y_{0}\right)_{+}=y-y_{0}$ if $y>y_{0}$ and 0 otherwise $)$ and " $(\ldots)_{-}$" means the negative part (i.e., $\left(y-y_{0}\right)_{-}=y_{0}-y$ if $y<y_{0}$ and 0 otherwise), $\gamma_{\mathrm{pm},+}, \gamma_{\mathrm{pm},-}$, and $X_{0, \mathrm{pm}}$, (the p-th specific value of the regressor $X_{m}$, so-called knot) are the regression constants pertaining to the proxy $X_{m}, m=1, \ldots, n$, to be calculated by the penalized least-squares method, using a multivariate adaptive regression splines (MARS) technique 
(see Krzyścin et al., 2005 for more detail description of this methodology).

Here we use parameterization Eq. (6) for all examined trend models. Initially the potential proxies are set: $\mathrm{Mg}$ II solar index, QBO wind at 10 and $30 \mathrm{hPa}$, solar, index of aerosols loading, detrended zonal wind anomaly along $60^{\circ} \mathrm{N}$ (or $60^{\circ} \mathrm{S}$ ), and detrended tropopause pressure. Not all proxies and their knots are finally used in the regression. MARS contains a trimming procedure to remove terms of Eq. (6), thereby only slightly affecting the model outcome or being cross correlated (Friedman, 1991). Number of the regressors used (including proxies and the knots) is the largest (10-15) for the case of the mid-latitudinal spring ozone which is quite small compared to the number of data points used $(\sim 100$ of the monthly means of total ozone for each selected season).

A detailed description of the proxies' signal in the total ozone data is outside the objective of this paper. Many such statistical analyses have appeared in recent years; see, for example, Steinbrecht et al., 2003; Reinsel et al., 2005; and Dhomse et al., 2005. Here we focus on the trend variability assuming the same set of proxies for various trend models as described in Sect. 3, to disclose how the different descriptions of the trend pattern affect the ozone restoration rate since the mid 1990s.

\section{Results}

Model (1) is run separately for each grid point and season. The data have been divided into the winter (comprising monthly total ozone means in December, January and February), spring (March, April, and May), summer (June, July, and August), and the autumn subset (September, October, and November). Thus, all the regression constants may exhibit seasonal dependence. In total, the analyzed data consists of 4 (seasons) $\times 216\left(2\right.$-D grid with resolution $\left.10^{\circ} \times 30^{\circ}\right)$ time series. We will discuss changes in the shape of the trend pattern (net long-term change) rather than the calculate trend slopes (usually expressed in DU or \% per decade) and compare the value of the trend term in 1995 and 2003 separately for each season.

The statistical errors of the trend estimates are calculated using the block bootstrap (BB) methodology (e.g. Künsch, 1989; and Politis and Ramano, 1994). The hypothetical time series of the ozone observations is constructed by a random drawing of the 3-month nonoverlapping subsets (blocks) from the noise term - residuals of model (1) - and adding them to the estimated trend and oscillatory part of model (1). Thus, separately for each season we draw (with replacement) a number of the block being equivalent to one year from the data beginning. In this way we also select three consecutive monthly residuals, pertaining to the chosen year. A classical bootstrap generates monthly representatives of the model's residuals and a random drawing should be accomplished from a set of the monthly residuals. Frequently the residu-
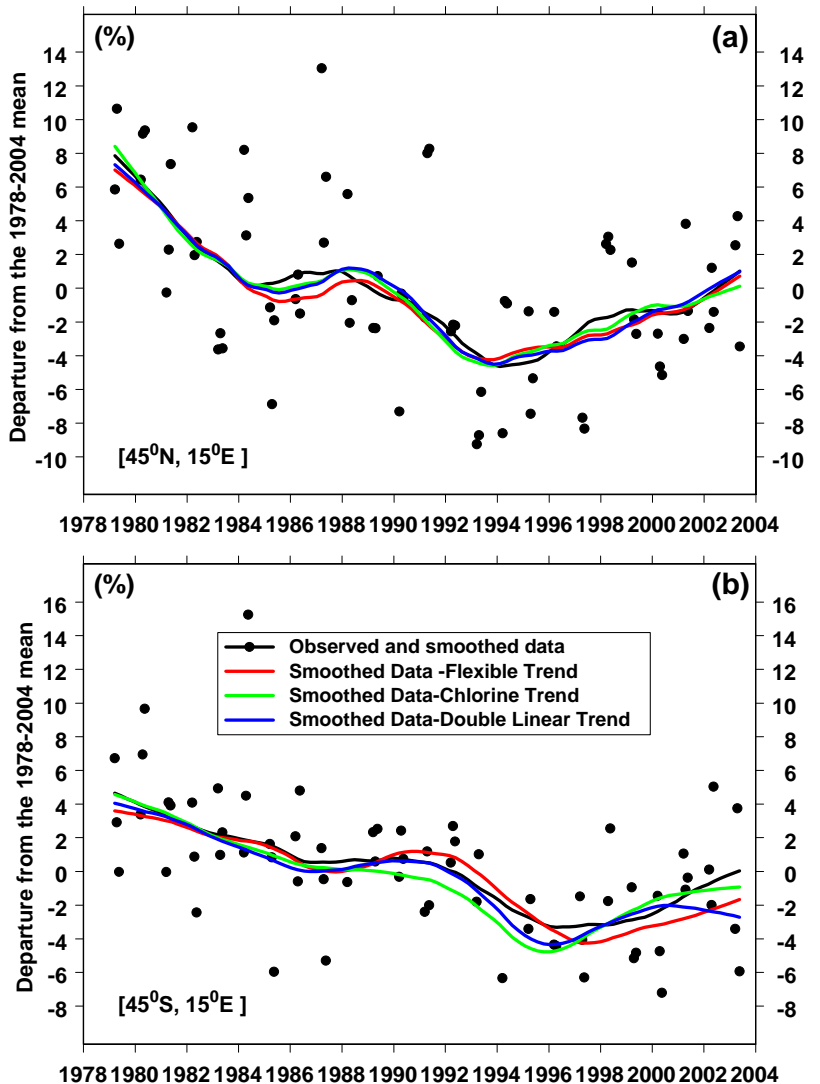

Fig. 3. Modelled and observed monthly means of total ozone in the spring seasons of $1979-2003$; (a) $\left(45^{\circ} \mathrm{N}, 15^{\circ} \mathrm{E}\right)$ grid point, (b) $\left(45^{\circ} \mathrm{S}, 15^{\circ} \mathrm{E}\right)$ grid point.

als in the neighboring months are correlated. Thus, at first the classical bootstrap requires an additional autoregressive model to extract random noise from the residuals and the next step is bootstrapping of the random part of Noise $(t)$. The seasonal blocks drawn from the noise term are weakly dependent for consecutive years because interannual oscillations in the data are mostly accounted for by the Oscillation $\left(X_{1}, \ldots, X_{n}\right)$ term of model (1). Thus, the precondition for applying $\mathrm{BB}$ is fulfilled, i.e. independence between the blocks of data. BB is much faster (at least 3 times fewer random drawings). The autoregressive structure of the noise term is automatically preserved and the extraction of the random term from the residuals is not necessary.

The variance explained by the model is practically independent of the examined trend pattern (Table 1) and exceeds $70 \%$ for most of the grid points. The lowest explained variance $(\sim 60 \%)$ is found for the NH high latitudes in summer and $\mathrm{NH}$ mid latitudes in autumn. It should be noted that results for winter (summer) and autumn (spring) for the $\mathrm{NH}$ (SH) high latitudes are not shown because of the astronomical limitations (polar night), and an increasing uncertainty in the observations taken under a high solar zenith angles' 
Table 1. The percent of the total variance explained by the regression models for NH High-Latitudes $\left(90^{\circ} \mathrm{N}-65^{\circ} \mathrm{N}\right)$, $\mathrm{NH}$ Mid-Latitudes $\left(65^{\circ} \mathrm{N}-30^{\circ} \mathrm{N}\right)$, Tropics $\left(30^{\circ} \mathrm{N}-30^{\circ} \mathrm{S}\right)$, SH Mid-Latitudes $\left(30^{\circ} \mathrm{S}-65^{\circ} \mathrm{S}\right)$, and SH High-Latitudes $\left(65^{\circ} \mathrm{S}-90^{\circ} \mathrm{S}\right)$. Standard errors (in the parentheses) provide the variability of the explained variance in these regions.

\begin{tabular}{|c|c|c|c|c|c|}
\hline Trend Model & $\begin{array}{l}\text { NH High- } \\
\text { Latitudes }\end{array}$ & $\begin{array}{l}\text { NH Mid- } \\
\text { Latitudes }\end{array}$ & Tropics & $\begin{array}{l}\text { SH Mid- } \\
\text { Latitudes }\end{array}$ & $\begin{array}{l}\text { SH High- } \\
\text { Latitudes }\end{array}$ \\
\hline \multicolumn{6}{|c|}{ Winter (December + January + February) } \\
\hline Double-linear & - & $71(10)$ & $79(9)$ & $85(4)$ & $79(7)$ \\
\hline Chlorine-EESC & - & $69(9)$ & $79(9)$ & $85(5)$ & $79(7)$ \\
\hline Flexible Curve & - & $71(9)$ & $81(4)$ & $88(4)$ & $82(6)$ \\
\hline \multicolumn{6}{|c|}{ Spring (March + April + May) } \\
\hline Double-linear & $71(8)$ & $74(8)$ & $74(9)$ & $71(13)$ & - \\
\hline Chlorine-EESC & $66(13)$ & $72(9)$ & $74(8)$ & $69(13)$ & - \\
\hline Flexible Curve & $68(10)$ & $77(8)$ & $76(9)$ & $74(12)$ & - \\
\hline \multicolumn{6}{|c|}{ Summer (June + July + August) } \\
\hline Double-linear & $56(12)$ & $67(11)$ & $85(5)$ & $71(7)$ & - \\
\hline Chlorine-EESC & $66(21)$ & $76(9)$ & $88(6)$ & $78(9)$ & - \\
\hline Flexible Curve & $63(15)$ & $73(10)$ & $85(6)$ & $71(7)$ & - \\
\hline \multicolumn{6}{|c|}{ Autumn $($ September + October + November $)$} \\
\hline Double-linear & - & $59(13)$ & $74(10)$ & $85(7)$ & $88(3)$ \\
\hline Chlorine-EESC & - & $60(13)$ & $72(12)$ & $84(6)$ & $87(4)$ \\
\hline Flexible Curve & - & $62(13)$ & $77(10)$ & $85(7)$ & $88(4)$ \\
\hline
\end{tabular}

regime of the observations. Small differences between the variances explained by various trend models are an indication of an equivalence of the models' performance and does not help to select the best model. Figure 3 illustrates that all trend models are able to reproduce the long-term variations in the total ozone data. Figure 4 supports that a correspondence between the modeled and measured values also exists for the unsmoothed data (monthly means).

Figure 5 shows the smoothed profile of a spring subset of the data for grid points $\left(45^{\circ} \mathrm{N}, 15^{\circ} \mathrm{E}\right)$, and $\left(65^{\circ} \mathrm{N}, 15^{\circ} \mathrm{E}\right)$ and superimposed are various trend time series from model (1). The trend curves are translated to 0 at the beginning of the time series for easier comparison between the trend patterns.

The flexible trend model yields a turnaround in the trend around 1996/1997 exactly corresponding to that assumed a priori by the other two models. It should be noted that the minimum in the ozone time series happened earlier, around 1994, probably due to the strong stratospheric aerosol forcing of the ozone layer after the Mt. Pinatubo eruption in June 1991 and the subsequent cleaning of the atmosphere.

It should be emphasized that the statistical uncertainties of the shape of the trend pattern preclude any detailed discussion of the differences between the trends. Figure 6 shows the mean trend line together with a $95 \%$ confidence range. The confidence range is calculated by the bootstrapping. The sample of $1000 \mathrm{BB}$ simulations of the trend curve value for each month have been considered. The upper and lower dashed curves in Fig. 6 represent the hypothetical trend patterns built using the ranked point 975 and the point 25 , respectively. The results by the flexible and chlorine trend models are shown in Figs. 6a and b, respectively, for the spring total ozone over the $\left(45^{\circ} \mathrm{N}, 15^{\circ} \mathrm{E}\right)$ grid point. It can be inferred that the ozone decline at two moments, spring 1995 and spring 2003, is calculated with about a $\pm 2 \%$ uncertainty corresponding to the $95 \%$ confidence interval. Thus, the ozone pattern shows statistically significant negative departures at these moments but an ozone restoration beginning in the mid 1990s is not apparent after visual inspection of both trend patterns. There is the possibility of the trend leveling off or even continuing to decline but with a smaller rate than that before spring 1995 (lower boundary of the trend confidence curve at the end of the time series will be above a hypothetical straight line drawn up to spring 2003 with a pre-1995 slope).

A statistical test has been applied to examine the differences between values of the flexible trend curve in 2003 and 1995. Namely, we calculate the difference for each bootstrap realization for each grid point. The total number of the differences is 1000 . Next, the differences are ranked in ascending order. Finally, we draw values at position 25 and 975, setting boundaries of the $95 \%$ confidence interval for the difference. Figure 7 illustrates the histogram of the differences for the $\left(65^{\circ} \mathrm{N}, 15^{\circ} \mathrm{E}\right)$ grid point. The $95 \%$ interval for the 2003 1995 difference is $[0.2 \%, 6.8 \%]$ for this grid point, which supports an appearance of the turnaround in the trend pattern since the mid 1990s. Reinsel et al. (2005) discussed the possibility of a more pronounced positive tendency in the trend pattern over high northern latitudes since the mid 1990s. However, the 2003-1995 difference is somewhere in the $[-3 \%, 2 \%]$ interval for the $\left(45^{\circ} \mathrm{N}, 15^{\circ} \mathrm{E}\right)$ grid point. 

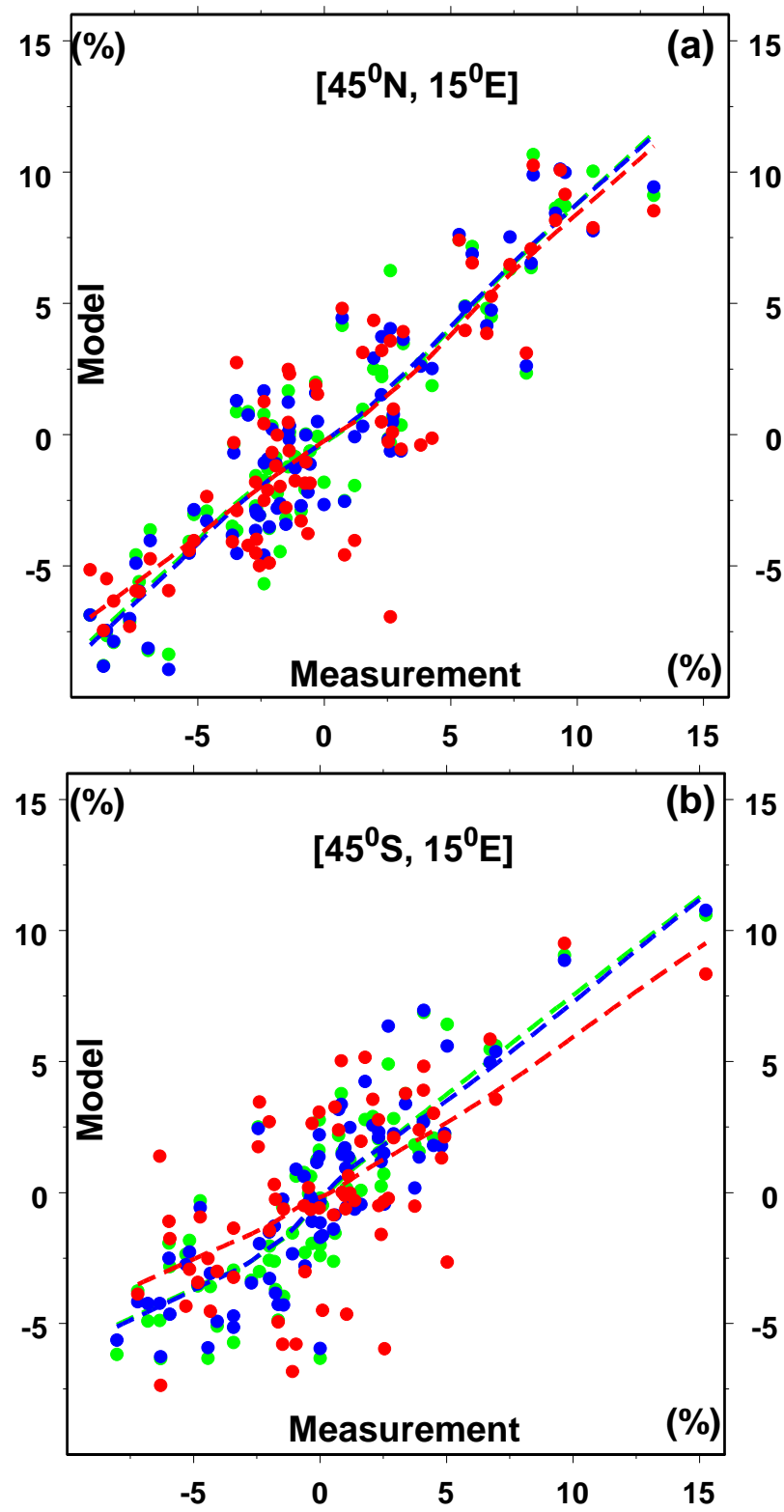

Fig. 4. The scatter plot of the modeled monthly means of total ozone versus the measured values in the spring seasons of the 1979-2003 period. Results by the double-linear trend model - blue circles, proportional to EESC - green circles, and by the flexible curve red circles. The dashed curves represent the smoothed data (by the LOWESS filter); (a) $\left(45^{\circ} \mathrm{N}, 15^{\circ} \mathrm{E}\right)$ grid point, (b) $\left(45^{\circ} \mathrm{S}, 15^{\circ} \mathrm{E}\right)$ grid point.

Thus, here it is too early to announce a turnaround in the European total ozone, which is in agreement with the Krzyścin et al. (2005) finding on recent trend changes in European total ozone.

The zonal (with $10^{\circ}$ resolution) distribution of the ozone change in the 1979-1995 and 1979-2003 period, due to the trend component of Eq. (1), is shown in Fig. 8 for all seasons.
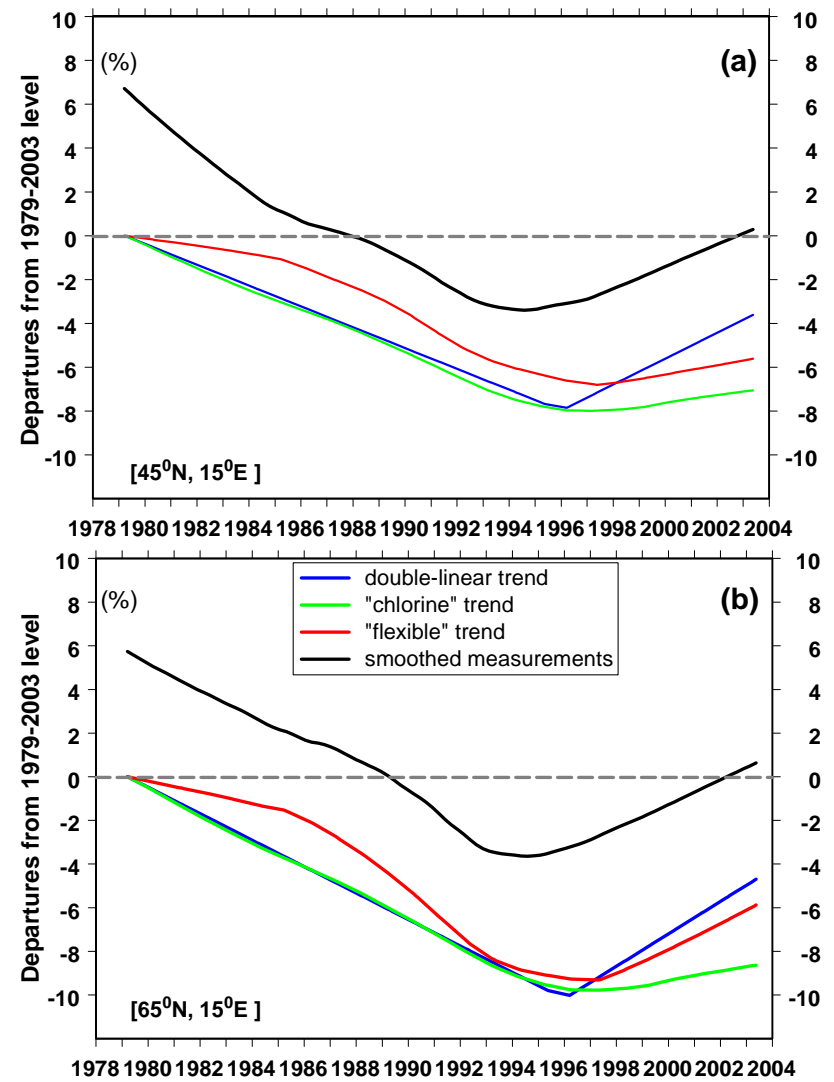

Fig. 5. Smoothed time series (black curve) of the monthly mean total ozone for the spring seasons in the 1979-2003 period and the superimposed trend pattern by various trend models (double-linearblue curve, proportional to EESC-green curve, and a flexible curvered curve). The trend patterns are translated to zero at the beginning of the time series for better cross comparison; (a) $\left(45^{\circ} \mathrm{N}, 15^{\circ} \mathrm{E}\right)$ grid point, (b) $\left(65^{\circ} \mathrm{N}, 15^{\circ} \mathrm{E}\right)$ grid point.

For each zone, the ozone change is calculated as an average value over grid points along the parallel. Thus, standard deviations shown in Fig. 8 give an idea of the longitudinal variability of the departures. Comparison between the various trend models leads to the following conclusions:

- the 2003 total ozone is still below the averaged (19792003) level over the extratropical regions, i.e. $~ 2-5 \%$ in NH. The ozone deficit in the $\mathrm{SH}$ is much larger and exhibits a much clear seasonal variability $(\sim 15 \%$ in autumn, $\sim 10 \%$ in winter, and $\sim 5 \%$ in spring and summer),

- the 2003 total ozone level is not lower than that in the mid 1990s,

- the ozone decline pattern in winter and autumn 2003 shows a similar zonal structure as in the mid of $1990 \mathrm{~s}$ (greater decline in the SH over mid- and high latitudes), 

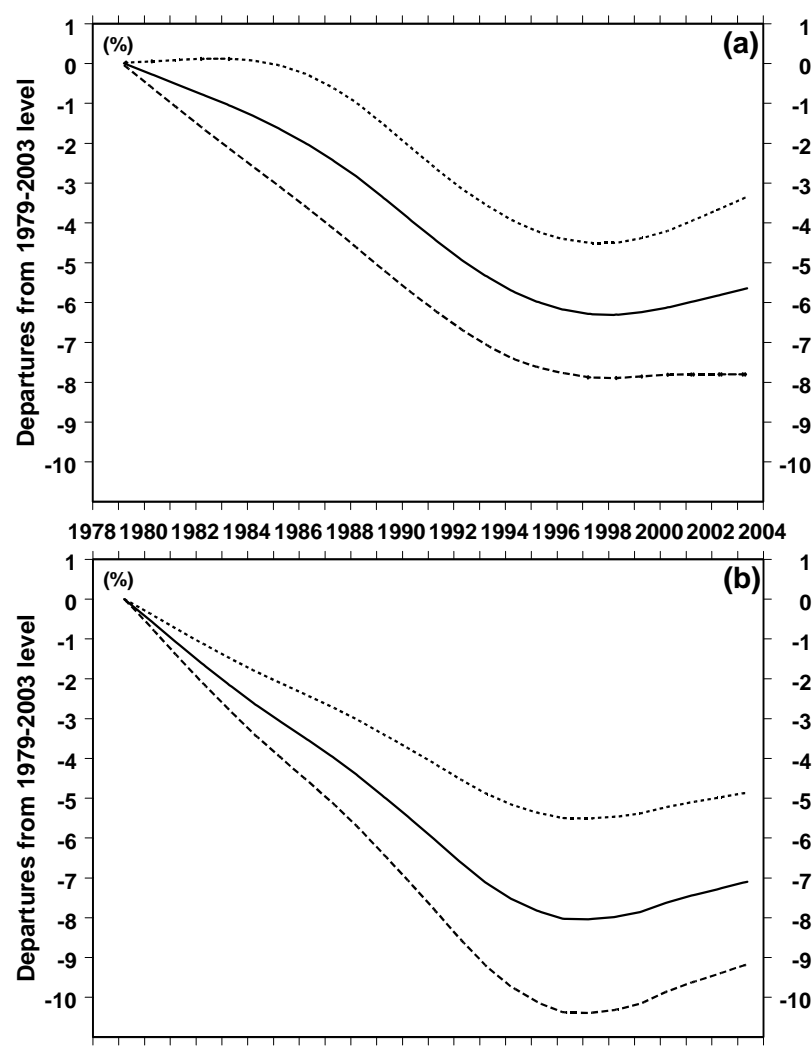

19781980198219841986198819901992199419961998200020022004

Fig. 6. The trend pattern determined by the flexible (a) and chlorine (b) trend models applied to spring total ozone data for the $\left(45^{\circ} \mathrm{N}, 15^{\circ} \mathrm{E}\right)$ grid point together with the $95 \%$ confidence limits.

- a kind of flattening of the zonal differences in spring and summer can be observed over the NH and SH in 2003, suggesting the appearance of positive ozone trends the beyond the tropics after 1995. This is supported by the results of the flexible and double-linear trend model,

- the 2003 ozone level, according to the chlorine model, is lower than that supported by other models but the 1995 levels agree with each other much better,

- high longitudinal variability of the ozone decline exists over extratropical regions especially during spring $(\mathrm{NH})$ and autumn (SH).

It should be emphasized that the longitudinal differences of the ozone decline are quite large precluding a determination of the models' difference at a high level of statistical confidence. For selected grid points (e.g. spring data for the $\left(65^{\circ} \mathrm{N}, 15^{\circ} \mathrm{E}\right)$ grid point presented in Fig. 7$)$, the statistically significant trend turnaround has been found but the analyses for neighboring grid points often yielded no statistically significant results.

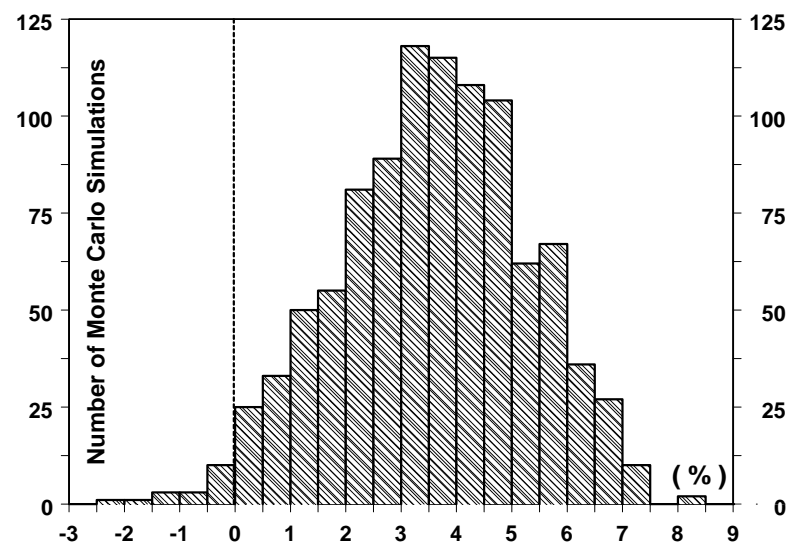

Fig. 7. Histogram of the differences (total ozone in spring 2003 minus that in spring 1995 in \% of the long-term means) induced by a trend in the $1995-2003$ period for the $\left(65^{\circ} \mathrm{N}, 15^{\circ} \mathrm{E}\right)$ grid point.

\section{Conclusions}

In a press release by the International Ozone Commission (IOC) summarizing the Quadrennial Ozone Symposium held in Kos, Greece, June 2004 (presently available at web address: http://ioc.atmos.uiuc.edu/press/ WMO-release-20040916.pdf) the following stages of the ozone recovery are defined: 1 - significant slowing in the downward trend of the ozone, 2 - significant upward trend in the ozone time series which remains after the removal of the "natural" factors affecting the ozone layer, 3 - returning to pre-1980 ozone levels in the stratosphere. Whether or not stage 1 (or 2) has been reached remains a subject of various recent analyses. Here we examine statistical trend models capable of detecting the expected turnaround in the total ozone trend. Statistical analyses have been applied to the total ozone time series by combining the satellite observations on various space platforms.

Our analyses supports stage 1 of the ozone recovery process (lessening of the ozone downward trend). Independent of the trend model used we have found that the 2003 level of total ozone, which remains after the removal of the fluctuations due to dynamical/chemical processes, is not lower than that in the mid of 1990s. This finding is rather a result of a consistent zonal pattern of the ozone change since 1995 which was found for all seasons and models (values at the end of the time series are always higher than that in 1995), than a rigorous statistical test applied to the differences. However, stage 2 of the recovery has been identified for selected grid points using the Monte-Carlo statistical test (based on MARS and BB methodology). Moreover, there were no grid points found with a statistically significant deepening of the ozone negative trend. For many grid points the data were still too noisy to make a conclusive statement of the direction of the ozone changes, thus it is too early to announce stage 2 . 


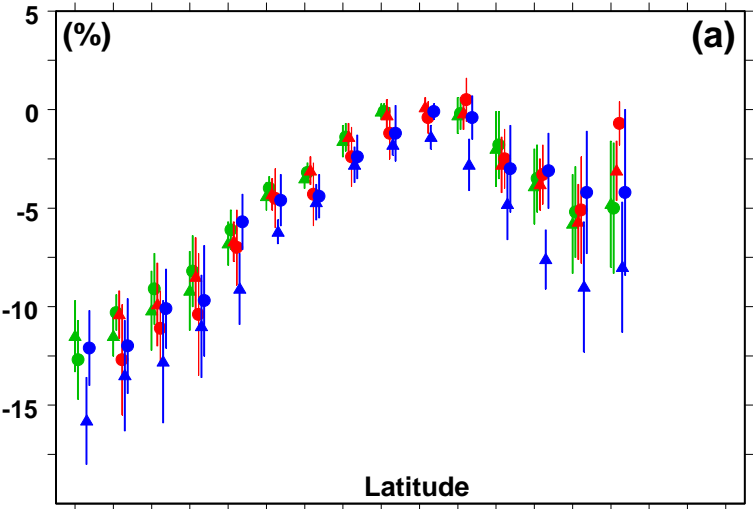

-85-75-65-55-45-35-25-15 -5 51525354555657585

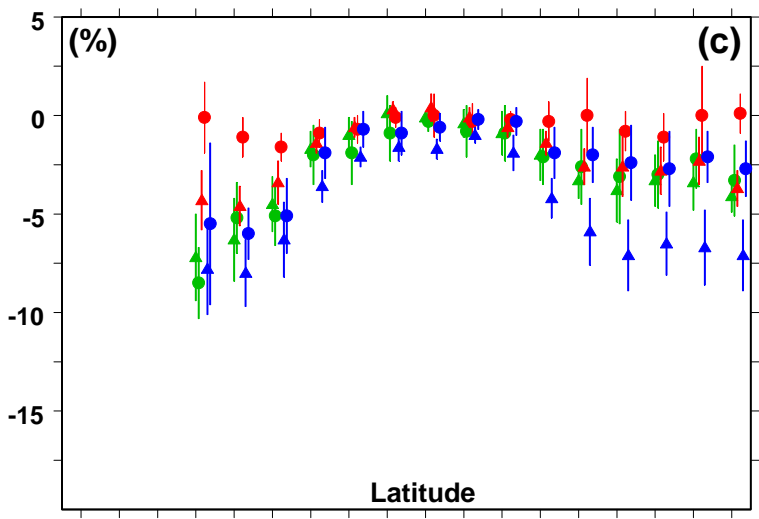

-85-75-65-55-45-35-25-15 -5 $5 \quad 1525354555657585$

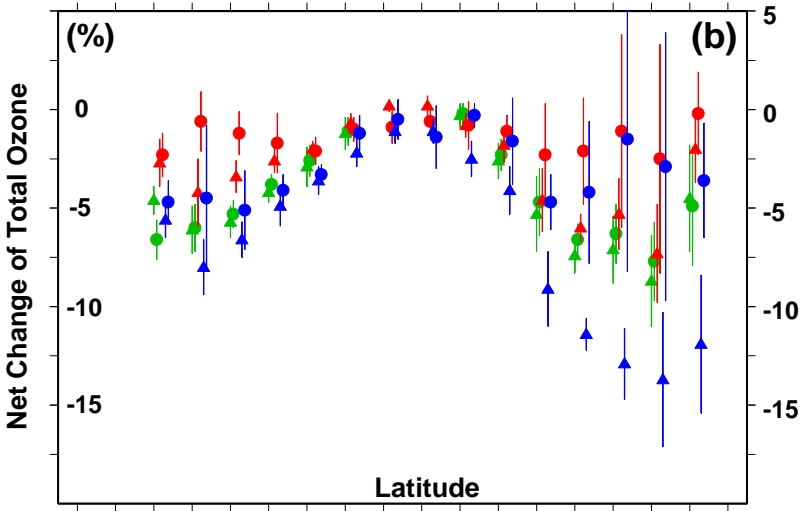

-85-75-65-55-45-35-25-15 -5 $5 \quad 1525354555657585$

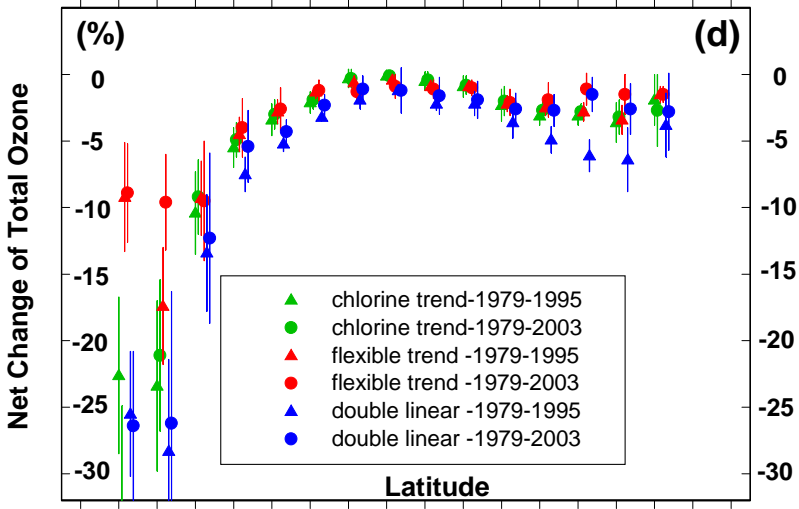

-85-75-65-55-45-35-25-15 -5 51525354555657585

Fig. 8. Zonal distribution of the net changes of total ozone due to trends in the 1979-1995 (triangles) and in the 1979-2003 (circles) period by various trend models (double-linear-blue, proportional to EESC-green, and a flexible curve-red symbols) in \% of the long-term (1978-2003) zonal means. Error bar represents the standard deviations derived from the individual grid point values along the corresponding parallel; (a) winter, (b) spring, (c) summer, and (d) autumn (see different scale for Y axis).

It is difficult to select the best trend model. The models' performances, characterized by the percent of the explained variance and correspondence between the modeled and observed long-term pattern of total ozone, are similar. The double-linear model provides changes, which are too sharp in trend pattern (as also discussed by Reinsel et al., 2005) yielding a deeper ozone minima and leading to an overestimation of the rate of ozone increase afterwards. It seems that the chlorine model does not account for all possible increases since the ozone minimum. It shows a supposed slight ozone increase following a small decreasing rate in the EESC after the peak. The results of the flexible trend model depend on an assumed level of smoothing when extracting the trend pattern from the ozone data (Krzyścin et al., 2005). Here a low-pass Lowess filtering has been applied, providing the possibility of only one local minimum which roughly corresponds to the EESC pattern. Over the NH and SH extratropics the MARS procedure, which was used to eliminate the redundant model's terms, never rejected the trend term regardless of its supposed form; Eq. (2), or Eq. (3), or Eq. (4). It is clear that more years of data are needed to identify the cause of the observed changes in the trend pattern. Comparison of models with various trend terms will help to quantify how changes in overall chlorine loading in the stratosphere affect the trend variability in the various regions of the Earth.

Acknowledgements. The study has been partially founded by the Polish Committee for Scientific Research, grant No. 2 P04D06728. The author would like to thank two reviewers for their efforts to improve the paper.

Topical Editor U.-P. Hoppe thanks two referees for their help in evaluating this paper.

\section{References}

Appenzeller, C., Weiss A. K., and Staehelin, J.: North Atlantic oscillation modulates ozone winter trends, Geophys. Res. Lett., 27, 1131-1134, 2000.

Bialek, M.: Long-term changes (1980-2003) in total ozone time series over northern hemisphere midlatitudes, Acta Geophysica, $54,1,60-70,2006$. 
Bojkov, R. D., Bishop, L., and Fioletov, V. E.: Total ozone trends from quality-controlled ground-based data (1964-1994), J. Geophys. Res., 100, 25 867-25 876, 1996.

Chipperfield, M. P.: A three-dimensional study of long-term midhigh latitude lower stratosphere ozone changes, Atmos. Chem. Phys., 3, 1253-1265, 2003.

Cunnold, D. M., Yang, E.-S., Newchurch, M. J., Reinsel, G. C., Zawodny, J. M., Russel III, J. M.: Comment on "Enhanced upper stratospheric ozone: Sign of recovery or solar effects?" by Steinbrecht et al., J. Geophys. Res., 109, D14305, doi:10.1029/2004JD0004826, 2004.

Dhomse, S., Weber, M., and Burrows, J.: On the possible causes of recent increases in $\mathrm{NH}$ total ozone from a statistical analysis of satellite data from 1979-2003, Atmos. Chem. Phys. Discuss., 5, 11331-11375, 2005.

Friedman, J. H.: Multivariate adaptive regression splines, The Annals of Statistics, 19, 1-50, 1991

Frith, S., Stolarski, R., and Barthia, P.: Implications of version 8 TOMS and SBUV data for long-term trend, Proceedings of the Quadrennial Ozone Symposium, 1-8 June 2004, Kos, Greece, edited by: Zerefos, Ch. S., University of Athens, 65-66, 2004.

Fioletov, V. E., Bodeker, G. E., Miller, A. ., McPeters, R. D., and Stolarski, R.: Global and zonal ozone variations estimated from ground-based and satellite measurements: 1994-2000, J. Geophys. Res. 107(D22), 4647, doi:10.1019/2001/JD001350, 2002.

Harris, J. M., Oltmans, S. J., Tans, P. P., Evans, R. D., and Quincy, D. M.: A new method for describing long-term changes in total ozone, Geophys. Res. Lett., 28, 4535-4538, 2001.

Harris, J. M., Oltmans, S. J., Bodeker, G. E., Stolarski, R., Evans, R. D., and Quincy, D. M.: Long-term variations in total ozone derived from Dobson and satellite data, Atmospheric Environment, 37, 3167-3175, 2003.

Hood, L. L. and Soukharev, B.: Interannual variations of total ozone at northern midlatitudes correlated with the stratospheric EP flux and potential vorticity, J. Atmos. Sci., 62(10), 3724-3740, 2005.

Kistler, R., Kalnay, E., Collins, W., Saha, S., White, G., Woollen, J., Chelliah, M., Ebisuzaki, W., Kanamitsu, M., Kousky, V., van den Dool, H., Jenne, R., and Fiorino, M.: The NCEP-NCAR 50Year Reanalysis: Monthly Means CD-ROM and Documentation, Bulletin of the American Meteorological Society, 82, 247-268, 2001

Krzyścin, J. W., Degórska, M., and Rajewska-Wiech, B.: Seasonal acceleration of the rate of total ozone decreases over Central Europe: Impact of tropopause height changes, J. Atmos. S.-P., 60, 1755-1762, 1998.

Krzyścin, J. W.: On the recovery of ozone over the NH midlatitudes: Statistical analyses of the long-term ozone measurements at Arosa, Proceedings of the Quadrennial Ozone Symposium, 18 June 2004, Kos, Greece, University of Athens, edited by: Zerefos, Ch. S., 382-383, 2004
Krzyścin, J. W., Jarosławski, J., and Rajewska-Wiech, B.: Beginning of the ozone recovery over Europe? - Analysis of the total ozone data from the ground-based observations, 1964-2004, Ann. Geophys., 23, 1685-1695, 2005.

Künsch, H.: The jackknife and the bootstrap for general stationary observations, Annals of Statistics, 17, 1217-1241, 1989.

Newchurch, M. J., Yang, E.-S., Cunnold, D. M., Reinsel, G. C., and Zawodny, J. M.: Evidence for slowdown in stratospheric ozone loss: First stage of ozone recovery, J. Geophys. Res., 108(D16), 4507, doi:10.1029/2003JD003471, 2003.

Newman, P. A., Kawa, S. R., and Nash, E. R.: On the size of the Antarctic ozone hole, Geophys. Res. Lett., 31, L21104, doi: 10.1029/2004GL020596, 2004.

Politis, D. N. and Ramano, J. P.: The stationary bootstrap, Journal of the American Statistical Association, 89, 1303-1313, 1994.

Randel, W. J., Wu, F., and Stolarski, R. S.: Changes in column ozone correlated with the stratospheric EP flux, Journal of Meteorological Society of Japan, 80, 849-862, 2002.

Reinsel, G. C., Weatherhead, E. C., Tiao, G. C., Miller, A. J., Nagatani, R. M., Wuebbless, D. J., and Flynn, L. E.: On detection of turnaround and recovery in trend for ozone, J. Geophys. Res., 107(D10), doi:10.1029/2001JD000500, 2002.

Reinsel, G. C., Miller, A. J., Weatherhead, E. C., Flynn, L. E., Nagatani, R. M., Tiao, G. C., and Wuebbles, D. J.: Trend analysis of total ozone data for turnaround and dynamical contributions, J. Geophys. Res., 110, D16306, doi:10.1029/2004JD004662, 2005.

Rosenfield, J. E., Frith, S. M., and Stolarski, R. S.: Version 8 SBUV ozone profile trends compared with trends from a zonally averaged chemical model, J. Geophys. Res., 110, D12302, doi:10.1029/2004JD005466, 2005.

Steinbrecht, W., Cloude, H., Köhler, U., and Choinka, K. P.: Correlation between tropopause height and total ozone: Implication for long-term changes, J. Geophys. Res., 103, 19 183-19 192, 1998.

Steinbrecht, W., Hassler, B., Claude H., Winkler, P., and Stolarski, R. S.: Global distribution of total ozone and lower stratospheric temperature variations, Atmos. Chem. Phys., 3, 14211438, 2003.

Varotsos, C., Cartalis, C., Vlamakis, A., Izanis, C., and Keramitsoglou, I.: The long-term coupling between column ozone and tropospheric properties, Journal of Climate, 17, 3843-3854, 2005.

Yang, E. S., Cunnold, D. M., Newchurch, M. J., and Salawitch, R. J.: Change in ozone trends at southern high latitudes, 2005, Geophys. Res. Lett., 32, L12812, doi:10.1029/2004GL022296, 2005.

WMO (World Meteorological Organization): Scientific assessment of ozone depletion: 1998. Global Ozone Research and Monitoring Project-Report No. 44, Geneva, 1999.

WMO (World Meteorological Organization): Scientific assessment of ozone depletion: 2002. Global Ozone Research and Monitoring Project-Report No. 47, Geneva, 2003. 